\title{
Chapter 2 Factors affecting the success of early salt-marsh colonizers: seed availability rather than site suitability and dispersal traits ${ }^{1}$
}

Erfanzadeh R., Garbutt A., Pétillon J., Maelfait J.-P. \& Hoffmann M.
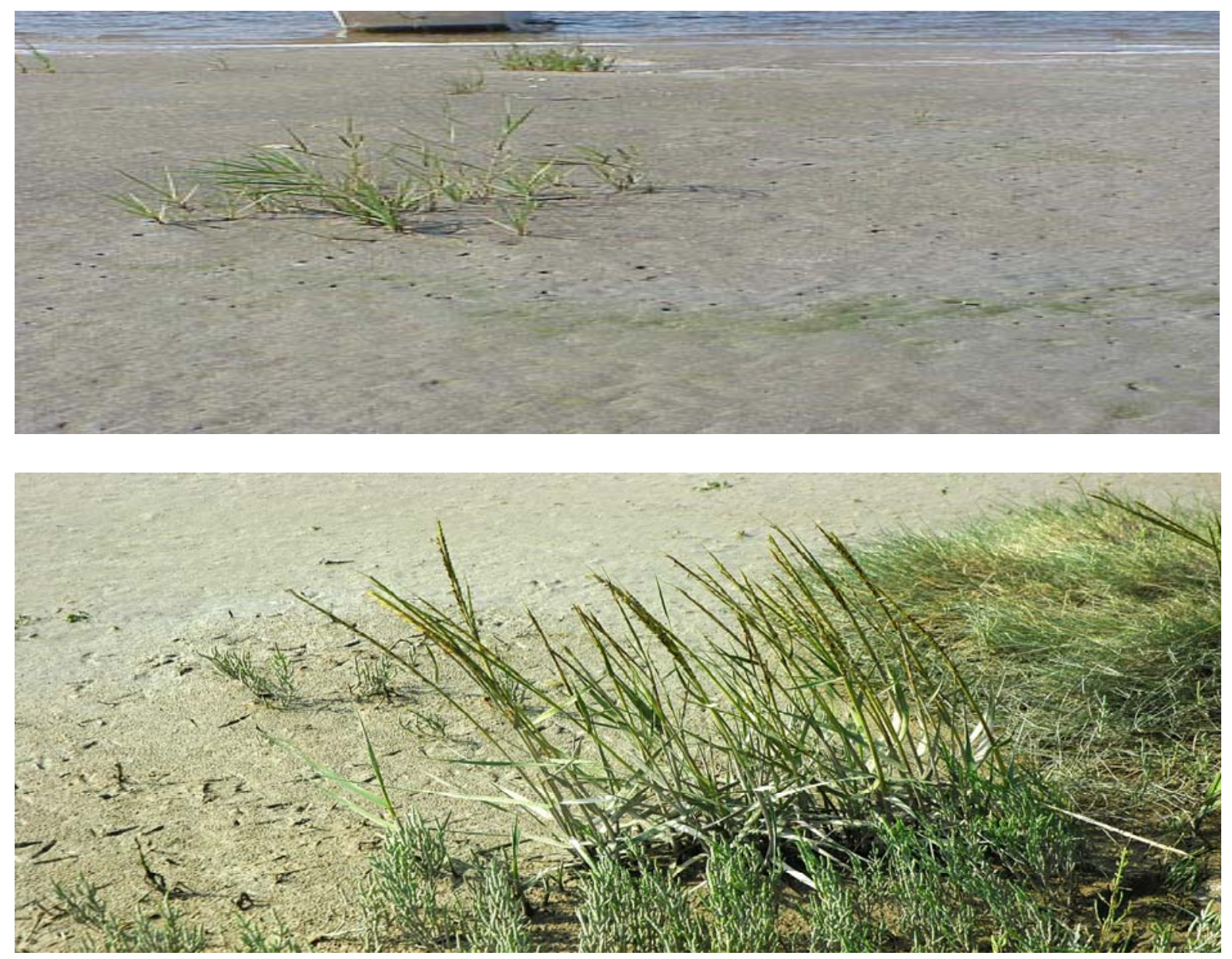

\footnotetext{
${ }^{1}$ This chapter has been invited for re-submission in Plant Ecology on $3^{\text {rd }}$ of April 2009. Field data were collected by the first author
} 


\subsection{Abstract}

Restoration of salt-marshes on newly created substrates provides an excellent opportunity to study plant colonization and its constraints. We evaluated the process of salt-marsh colonization in early successional stages and investigated how the sequence of species establishment is related to the abundance of species in neighbouring, long-existing saltmarshes, site suitability, seed production and dispersal traits of the involved plant species. Species distribution and colonization data were collected, using vegetation relevés, that were collected in the restoration site during three consecutive periods in 175 permanent $2 \mathrm{~m} \times 2 \mathrm{~m}$ plots. The plots were located along eight randomly chosen transects which were established perpendicular to the shoreline. To describe the only local diaspore source for new salt-marsh plant species, vegetation data were also collected in the adjacent salt-marsh in 66 permanent plots in the same time sequence. We used seed length, width and mass as dispersal traits, and Ellenberg moisture, salinity and nutrient indices as indicators of site suitability. To describe the importance of seed availability on initial colonization, seed production in the reference site and seed bank in the restoration site were also investigated.

The results showed that the establishment of salt-marsh species in the restoration site was good and fast, the cover of new colonizers in the restoration site was unrelated to their cover in the adjacent salt-marsh. Seed availability appeared to be a more important factor in explaining the sequence of species establishment than salt and nutrient-limitation tolerance. The first colonizers are known as massive seed producers, shorter seed length and lower seed mass, which probably increased buoyancy. Among dispersal and site traits, seed length and mass, and in a less extent salinity and nutrients, indicated a relationship with new colonizers. Despite few species have not appeared in vegetation and seed bank in the restoration site yet, the existence of an old salt-marsh adjacent to the restoration site is shown to be vital for fast colonization of newly created intertidal areas. 
Key words: Site suitability, Seed dispersal traits, Seed availability, New colonizers.

Nomenclature: Lambinon et al. (1998). 


\subsection{Introduction}

The successful restoration of plant communities depends on the availability of diaspores of the target species and favourable abiotic conditions for seedling establishment and growth (Bakker et al. 1996). Of all species included in local and regional floras, only some take an important part in early primary succession; such species must be capable of colonizing and reaching a large cover in the restoration site (Prach \& Pysek 1999). Succession at a new site by colonization of plant species from higher spatial scales is controlled by local and regional variables (Caley \& Schluter 1997; Hillebrand \& Bleckner 2002; Kirmer et al. 2008). Both plant species richness and composition depend on the presence of suitable abiotic conditions (Grubb 1977; Urbanska 1997; Peach \& Zedler 2006). Site conditions typical of a pioneer stand (e.g. nutrient deficiency in terrestrial habitats) were proven to be important factors for the colonization by initial adapted species (Rehounkova \& Prach 2006; Kirmer et al. 2008). Physical factors, e.g. salinity, anoxia, $\mathrm{pH}$ or sedimentation, strongly affect the germination and recruitment of species in salt-marshes, particularly at lower marsh elevations (Gray 1992; Huckle et al. 2000; Tessier et al. 2000).

Population dynamics of plant species at the beginning of primary succession are not only determined by local niche-based processes, but also by seed dispersal processes (Kirmer et al. 2008), which are assumed to be particularly important in late successional stages (Bossuyt \& Honnay 2008). Seed availability (limitation) can be a major limiting factor in ecological restoration projects (Ozinga et al. 2004; Dausse et al. 2008). Target species can establish through dispersal from source plant communities. The degree of seed limitation is likely to depend on the abundance of adults in the local and adjacent species pool and specific dispersal traits of the plant species (Zobel 1997; Ozinga et al. 2005). It is expected that the plant species that exist in the local and regional areas would have the ability to colonize a newly available site (Wolters et al. 2005a). Distances to seed sources (Frenzen et al. 1988), 
spatial distribution of seed sources (Wood \& del Moral 1987), neighbourhood influences (Ryser 1990) and the movement of seeds from productive areas into the new site (Shmida \& Ellner 1984) are all likely important determinants of the outcome of colonization.

In salt-marsh restoration, the fastest development of vegetation is expected from the community species pool within a target area, either from established vegetation or the belowground seed bank (Wolters et al. 2008). Colonization of plants from the species pool is a twostep process: seed availability and germination. Seed availability is the first step needed to establish a population from seed, but does not guarantee seed germination. Seed dispersal alone, only makes a species a member of the potential flora of the site, not its actual flora (Major \& Pyott 1966). Species abundance in the local species pool was also found to be important for determining the order of colonization in salt-marshes with late establishers being less abundant on the adjacent marshes than intermediate colonizers (Wolters et al. 2008). Dispersal ability affects the probability of a plant species to colonize a new substrate (Wilson \& Traveset 2000), initial colonizers having a high dispersal ability compared to species that would colonize later. The tidal current is the most important agent to disperse plant seeds in salt-marshes. Although seeds of most salt-marsh species can immerse or float in seawater (Packham \& Willis 1997), buoyancy of seeds and flotation period are different in various species, which affects the dispersal ability of salt-marsh species (Huiskes et al. 1995). Several factors affect the buoyancy of seeds, such as seed shape (defined as length/width: Grime et al. 1988) and seed mass; with increasing seed shape and seed mass, seed buoyancy is reduced (Poschlod et al. 2005). It is expected that initial colonizers in a salt-marsh have seeds with a shorter length, wider width and lower seed mass than the species of later successional stages. In terrestrial habitats, species tend to present heavier seeds in late successional than in early successional ones (Fenner 1987; Leishman 1999), but few studies have examined such relationship in salt-marsh habitats. Lastly, seed germination is a complex 
physiological process depending on many environmental conditions (Mayer \& PoljakoffMayber 1982). It can be expected that species with high salinity tolerance germinate and establish earlier (Wolters et al. 2008). Of all species included in a regional and local flora, only some take an important part in early primary succession; such species must be capable of colonizing and reaching a large cover in a restoration site (Prach \& Pysek 1999). There are few studies that have synchronically examined factors affecting mechanisms for distribution and colonization in a newly created salt-marsh in Europe.

The present paper aims to determine the factors affecting both plant colonization and distribution in a newly created salt-marsh in the IJzer estuary, Belgium, by addressing the following questions: what seed and plant traits are important in the establishment of primary colonizers in a salt-marsh restoration scheme, and is colonization limited by seed availability or by abiotic conditions? We first tested the hypothesis that seed dispersal traits may limit plant colonization by comparing the seed availability in the reference site and the seed bank in the restoration site. First year colonizers are hypothesized to show shorter seed length, wider seed width and lower seed mass than those colonizing in later years. We then tested the hypothesis that, beside seed availability, the success of restoration can be influenced by plant traits (as a surrogate of site suitability) by comparing the seed bank and the plant presence and cover in the restoration site. In particular highly salt and nutrient-limitation tolerant species are expected to be earlier colonizers than less salt tolerant and less nutrient-limitation tolerant species.

\subsection{Material and Methods}

\subsubsection{Study area}

The study area is situated in the IJzer estuary, part of the IJzermonding nature reserve on the Belgian North Sea coast. A new salt-marsh (ca. 14ha) was created after the removal of 
buildings and slurry material during large nature restoration works in the period 1999-2002. (Hoffmann 2006). The objective of the restoration project was to restore beach-dune-saltmarsh ecotones by the dispersal of target species from the local species pool (adjacent saltmarshes and sand dunes) by natural colonization. In the newly created intertidal area (hereafter called the restoration site), gradual elevational gradients were created, ensuring different inundation frequency conditions in different elevations. The area was exposed to tidal inundation from the beginning of 2002 onwards. Subsequently, the unique opportunity was created to study the sequence of species establishment in relation to site suitability, seed availability, species pools and traits.

From a pilot study of the seed bank of some intertidal mud flats, newly created after removal of 3 to $4 \mathrm{~m}$ of slurry material (Stichelmans 2002, cit. in Hoffmann \& Stichelmans 2006) at the study site, we could conclude that no relevant salt-marsh species seed bank was available in the formerly buried, newly exposed mud flat soil. This indicates that the soil of the rest of the restoration site that was buried for several decades would also be free of saltmarsh species seeds. Colonization of the site therefore relied entirely on diaspores from external sources. In salt-marshes, hydrochory has been reported as the preferential mode for seed dispersal, which is mostly of a local character, even though very few seeds can disperse over long distances, up to $60 \mathrm{~km}$ per week (Koutstaal et al. 1987; Huiskes et al. 1995). The presence of a naturally established salt-marsh in the adjacent IJzer estuary was considered here as the only local source of diaspores for the restoration site because the most proximate salt-marsh areas are approximately $50 \mathrm{~km}$ southwest and $42 \mathrm{~km}$ northeast of the present study area.

The old adjacent natural salt-marsh (hereafter called the reference site) consists of two parts (Fig. 1.4): a large one $(\mathrm{O} 1)$ at the west and in free tidal current contact with the restoration site $(\mathrm{N})$, and a smaller $(\mathrm{O} 2)$ located in the south of the restoration site and 
separated from it by a dike (with a $7 \mathrm{~m}$ height), not allowing direct tidal current contact between both.

\subsubsection{Seed production in the reference site}

Seeds produced by salt-marsh species were collected from the reference site to estimate seed production. Three sites were randomly selected, one in the southern part $(\mathrm{O} 2)$ and two in the west part (O1). At each site, 10 samples were randomly collected in plots of $50 \mathrm{~cm} \times 50 \mathrm{~cm}$ on four occasions between the beginning of September and the end of October, 2008. Seeds were collected before they were completely ripened and naturally dispersed. Each sample contained all flowering stems for perennials and all entire plants for annuals per quadrates $50 \mathrm{~cm} \times$ $50 \mathrm{~cm}$. The average total seed production was measured in each spike for grasses and each flower (or capitule) for flowering species. After the number of spikes and flowers was counted, we counted the number of seeds for one unit randomly chosen for each quadrate. Mean seed production by unit was estimated by using the average seed production across quadrates where the plant was present. Finally, the total seed production was calculated for the entire reference site by multiplying the number of seeds per unit, the number of units per quadrate and the total area of the site divided by the surface of the quadrate.

\subsubsection{Seed bank in the restoration site}

The seed bank of the restoration site was collected in 10 randomly chosen $2 \mathrm{~m} \times 2 \mathrm{~m}$ plots in close proximity of permanent plots and across the restoration site. The seed bank data were sampled in 2006, four years after the site was first exposed to tidal inundation. In each plot, with an auger with a diameter of $3 \mathrm{~cm}$, an average of 25 soil cores were randomly collected, to a depth of $15 \mathrm{~cm}$, ensuring taking samples of all newly accreted marine sediments. The samples were collected in March after natural stratification during winter. The big parts of

litter layer were removed in the field and samples transferred to the laboratory. The 
methodology of ter Heerdt et al. (1996) was used to concentrate the soil seed bank samples, which were washed through a coarse $(2 \mathrm{~mm}$ mesh width) and a fine $(0.18 \mathrm{~mm}$ mesh width) sieve, removing all roots and coarse vegetative parts on the first sieve, and withholding the vast majority of seeds on the second, while most of the soil material flushed away through the latter sieve. The concentrated samples were spread in a thin layer (maximum $0.4 \mathrm{~cm}$ thick) in $40 \mathrm{~cm} \times 40 \mathrm{~cm}$ trays filled with sterilized potting soil. The trays were placed in a greenhouse in a random order with a natural light regime and were kept moist by regular rain water spraying. Air temperature varied between $14^{\circ} \mathrm{C}$ and $25^{\circ} \mathrm{C}$ throughout the experiment. 24 control trays, filled with the same sterilized potting soil, were randomly placed among the seed bank trays in order to test for possible greenhouse and potting soil seed contamination.

Seedlings were identified as soon as possible after germination, counted and removed or, if they could not be identified immediately, transplanted to pots to allow further growth. After 6 months, when no further seedlings germinated, the trays were left to dry for two weeks. This allowed the sample to be crumbled to expose deeper buried seeds to the light. After watering the samples for another 3 weeks and controlling the light regime in 8 hour dark/16 hour light conditions, no new seedlings emerged. Finally, the residual soil was checked for remaining seeds by viewing small random samples taken from trays under a microscope and probing seeds with a needle in order to distinguish any remaining, potentially viable seeds. Since, the number of seeds that remained in the investigated soil samples was very low (none in most cases, and always less than 3 per tray), we did not need to correct for remaining seeds. Mean number of seeds per $\mathrm{m}^{2}$ was finally calculated from the 10 cores for each species recorded in the seed bank samples taken from the restoration site.

\subsubsection{Vegetation cover within the restoration and reference sites}

Vegetation data were collected in the restoration site and adjacent reference salt-marsh in permanent plots. Cover of all vascular plant species was visually estimated, using a decimal 
scale (Londo 1976). According to the size of the surface of the restoration site and adjacent salt-marsh, 175 and 66 permanent $4 \mathrm{~m}^{2}(2 \mathrm{~m} \times 2 \mathrm{~m})$ plots were collected. Vegetation was sampled in 2003, 2005 and 2007 along eight and five randomly chosen transects in restoration site and adjacent salt-marsh, respectively, which were established perpendicular to the main elevation gradient (inundation frequency). Plots were distributed evenly across transects at $3 \mathrm{~m}$ intervals to account for vegetation heterogeneity across the study sites.

\subsubsection{Plant traits and site suitability}

The selection of plant traits was based on previous studies by Wolters et al. (2008) and prior expectations about possible effect on the abundance of new colonizers. We selected six traits related to environmental factors and seed morphology: the Ellenberg indices for nutrients, salinity and moisture (Ellenberg et al. 1991) and three seed traits: seed length, seed width and seed mass. Seed length and width are correlated to seed shape, which is related to seed buoyancy (Poschlod et al. 2005). Ellenberg indices were used to estimate the species tolerance to environmental factors and seed traits were used to estimate the seed dispersal ability. Dispersal traits were abstracted from the Biolflor database (www.ufz.de/biolflor/index.jsp), and the Leda trait database (Knevel et al. 2003, www.leda-traitbase.org) for salt-marsh species.

\subsubsection{Statistical analyses}

The average cover of each species in the restoration site and adjacent reference salt-marsh were correlated by Pearson correlation index for each year separately. For analyzing changes in species cover along time, average covers of dominant species (i.e. having a cover of at least $5 \%$ during our study) were compared among years by T-tests for dependent samples for each site separately (after Bonferonni correction for multiple comparisons). Plant trait analysis was performed in order to detect the differences in trait promotion or inhibition during succession 
from 2003 until 2007. For each plant trait (three Ellenberg's indicators and three seed traits) weighted averages were calculated at the plot level in all three years separately, i.e. 2003, 2005 and 2007. All trait data were continuous. The species traits were compared between three years (2003, 2005 and 2007) using repeated measurements General Linear Modelling (GLM) and a pairwise LSD test. Calculations were done with SPSS 15.0. All data met normal distribution criteria according to Kolmogorov-Smirnov tests (after $\log _{10}(\mathrm{x}+1)$ transformation for plant covers).

\subsection{Results}

\subsubsection{Seed production at the reference site}

Seed production as observed for different salt-marsh species is given in Table 2.1. In some species, no flowering stems were observed in any of the four sampling sessions. Some perennial graminoid species were contaminated by fungi. For Aster tripolium, each flowering branch contained on average $85 \pm 14$ capitules. Each capitule contained $17 \pm 7.6$ seeds. For Elymus athericus, most florets were empty, but by taking into account the percentage cover of this species, total seed production is still being estimated to be no less than $6.7 \times 10^{5}$ seeds for the reference site. For Puccinellia maritima, flowering stems were never observed. For Spartina townsendii, most spikes were contaminated with Claviceps purpurea and/or empty.

Table 2.1. Seed production in different salt-marsh species at the study site.

\begin{tabular}{l|ccc}
\hline Species & Unit & Seeds/unit & Seeds/reference site/year \\
\hline Aster tripolium & Flowering stem & $1445 \pm 650$ & $18.2 \times 10^{8}$ \\
Atriplex littoralis & Individual & $111 \pm 29$ & $4.1 \times 10^{6}$ \\
Atriplex prostrata & Individual & $365 \pm 78$ & $1.3 \times 10^{7}$ \\
Elymus athericus & Spike & $0.8 \pm 1.4$ & $6.7 \times 10^{5}$ \\
Limonium vulgare & Flowering stem & $322 \pm 284$ & $6.0 \times 10^{8}$ \\
Puccinellia maritima & Plant & 0 & 0 \\
Salicornia europaea & Individual & $62 \pm 56$ & $8.6 \times 10^{8}$ \\
Spartina townsendii & Spike & 0 & 0 \\
Suaeda maritima & Individual & $146 \pm 158$ & $4.9 \times 10^{8}$ \\
Triglochin maritimum & Flowering stem & $12 \pm 15$ & $6.7 \times 10^{5}$ \\
\hline
\end{tabular}




\subsubsection{Seed bank at the restoration site}

The number of species within the seed bank of the restoration site was limited (Table 2.2). The density of seeds in the seed bank in the restoration site was entirely dominated by annual species. Characteristic perennial salt-marsh species, present in the above-ground vegetation of the reference site, were not recorded within the restoration site seed bank (Elymus athericus, Limonium vulgare, Plantago maritima, Puccinellia maritima, Artemisia maritima and Spartina townsendii). Aster tripolium and Triglochin maritimum were only recorded from one core with one germinating seed each.

Table 2.2. Seed density (germinating seeds $/ \mathrm{m}^{2}$ ) for salt-marsh species in the restoration site in 2006 , four years after the site was first exposed to tidal inundation, also to be considered as the first exposure period to seed rain. The average of seed density was estimated in $0-15 \mathrm{~cm}$ depth.

\begin{tabular}{l|c}
\hline Species & Seed density (mean \pm SE) \\
\hline Aster tripolium & $3.13 \pm 3.13$ \\
Atriplex littoralis & $48.47 \pm 28.85$ \\
Atriplex prostrata & $69.36 \pm 34.95$ \\
Chenopodium rubrum & $971.53 \pm 424.49$ \\
Glaux maritima & $5.61 \pm 5.61$ \\
Salicornia spp. & $3431.62 \pm 1580.22$ \\
Spergularia spp. & $651.89 \pm 315.85$ \\
Suaeda maritima & $201 \pm 63.25$ \\
Triglochin maritimum & $2.46 \pm 2.46$ \\
\hline
\end{tabular}

\subsubsection{Vegetation cover within the restoration site and adjacent local salt-marsh}

In 2003, one year after being exposed to tidal flooding, $79 \%$ of the species present in the adjacent old salt-marsh germinated within the restoration site (Table 2.3). Species from the adjacent species pool that established during the first year were predominantly annuals. The restoration site was dominated by the annual species Suaeda maritima, Atriplex spp., Salsola kali and Salicornia europaea. The adjacent salt-marshes were dominated by the perennial species Elymus athericus, Puccinellia maritima and Limonium vulgare. There was no 
significant correlation between species cover within the restoration and the reference sites in the first year of colonization.

In 2005 , after three years of tidal inundation, $81 \%$ species growing in the adjacent saltmarshes were recorded in the restoration site. Glaux maritima and Parapholis strigosa, absent in 2003 , were recorded in 2005 within the restoration site for the first time. There was a significant correlation between species abundance within the restoration and the reference sites in $2005(p<0.01, r=0.50)$.

In $2007,84 \%$ species growing in the reference salt-marsh were recorded in the vegetation of the restoration site. Species abundance in the new salt-marsh was positively correlated to species abundance in the adjacent salt-marsh $(p<0.01, r=0.44)$. Plantago maritima, which was only present in the old salt-marsh part O2 (Fig. 1.4), isolated from the restoration site by a dike was not found back in the investigated plots of the restoration site; it was however present with very few individuals outside the restoration site plots in 2005 and 2007. Triglochin maritimum and Artemisia maritima (the latter outside sampled vegetation plots), both also restricted to the old salt-marsh part $\mathrm{O} 2$, remained entirely absent from the restoration site. The percentage cover of all the dominant species increased along time in the restoration whereas it remained constant in most cases in the reference site (Table 2.3). 
Table 2.3. Average ( \pm SE) species cover (\%) in restoration and reference sites between 2003 and 2007. Vegetation data were collected from mid-August until end-September. a, b and c indicate significant differences between years and within each site for dominant species (bold in the table; according to t-test for dependent samples, after Bonferonni correction for multiple comparisons). Saltmarsh species not present in the plots but present at the site are given too. $\left(^{*}\right)$ : present in the reference site but not (yet) within the permanent plots; $\left({ }^{* *}\right)$ present in the restoration site but not (yet) in the permanent plots.

\begin{tabular}{|c|c|c|c|c|c|c|}
\hline \multirow[t]{2}{*}{ Species } & \multicolumn{3}{|c|}{ Restoration site } & \multicolumn{3}{|c|}{ Reference site } \\
\hline & 2003 & 2005 & 2007 & 2003 & 2005 & 2007 \\
\hline Agrostis stolonifera & $2.02 \pm 0.81$ & $1.89 \pm 0.47$ & $2.26 \pm 0.54$ & $0.21 \pm 0.10$ & $0.36 \pm 0.17$ & $0.41 \pm 0.2$ \\
\hline Artemisia maritima $\left({ }^{*}\right)$ & $0.00 \pm 0.00$ & $0.00 \pm 0.00$ & $0.00 \pm 0.00$ & $0.00 \pm 0.00$ & $0.00 \pm 0.00$ & $0.00 \pm 0.00$ \\
\hline Aster tripolium (**) & $0.00 \pm 0.00$ & $0.00 \pm 0.00$ & $0.00 \pm 0.00$ & $2.51 \pm 0.84$ & $2.38 \pm 0.74$ & $3.01 \pm 1.14$ \\
\hline Atriplex littoralis & $0.91 \pm 0.41$ & $0.20 \pm 0.07$ & $0.05 \pm 0.02$ & $1.24 \pm 1.07$ & $0.09 \pm 0.03$ & $0.09 \pm 0.03$ \\
\hline Atriplex prosterata & $1.29 \pm 0.52$ & $0.72 \pm 0.25$ & $0.13 \pm 0.02$ & $0.95 \pm 0.70$ & $0.22 \pm 0.05$ & $0.07 \pm 0.03$ \\
\hline Beta vulgaris ssp. maritima & $0.04 \pm 0.02$ & $0.01 \pm 0.01$ & $0.01 \pm 0.01$ & $0.07 \pm 0.04$ & $0.07 \pm 0.04$ & $0.05 \pm 0.02$ \\
\hline Cakile maritima & $0.02 \pm 0.01$ & $0.01 \pm 0.01$ & $0.08 \pm 0.06$ & $0.02 \pm 0.02$ & $0.00 \pm 0.00$ & $0.01 \pm 0.01$ \\
\hline Carex arenaria & $0.19 \pm 0.04 \mathbf{a}$ & $3.36 \pm 0.99 \mathbf{b}$ & $5.57 \pm 1.15 \mathrm{c}$ & $0.09 \pm 0.03 \mathbf{a}$ & $1.53 \pm 0.91 \mathbf{a}$ & $2.00 \pm 0.84 \mathbf{a}$ \\
\hline Chenopodium album & $0.06 \pm 0.02$ & $0.07 \pm 0.02$ & $0.03 \pm 0.01$ & $0.00 \pm 0.00$ & $0.04 \pm 0.02$ & $0.00 \pm 0.00$ \\
\hline Chenopodium glaucum & $0.00 \pm 0.00$ & $0.02 \pm 0.01$ & $0.02 \pm 0.01$ & $0.00 \pm 0.00$ & $0.00 \pm 0.00$ & $0.01 \pm 0.01$ \\
\hline Chenopodium rubrum & $0.31 \pm 0.05$ & $0.15 \pm 0.06$ & $0.02 \pm 0.01$ & $0.12 \pm 0.04$ & $0.01 \pm 0.01$ & $0.00 \pm 0.00$ \\
\hline Cirsium arvense & $0.36 \pm 0.14$ & $0.88 \pm 0.25$ & $0.57 \pm 0.19$ & $0.26 \pm 0.11$ & $0.24 \pm 0.08$ & $0.51 \pm 0.35$ \\
\hline Diplotaxis tenuifolia & $0.21 \pm 0.06$ & $0.12 \pm 0.03$ & $0.00 \pm 0.00$ & $0.01 \pm 0.01$ & $0.05 \pm 0.02$ & $0.01 \pm 0.01$ \\
\hline Elymus athericus & $0.36 \pm 0.23 \mathbf{a}$ & $1.82 \pm 0.72 \mathbf{b}$ & $3.36 \pm 1.05 \mathrm{c}$ & $24.01 \pm 3.77 \mathbf{a}$ & $25.74 \pm 3.67 \mathbf{a b}$ & $33.72 \pm 4.46 \mathbf{b}$ \\
\hline Erigeron canadensis & $0.01 \pm 0.01$ & $0.40 \pm 0.19$ & $0.60 \pm 0.19$ & $0.01 \pm 0.01$ & $0.02 \pm 0.02$ & $0.16 \pm 0.04$ \\
\hline Festuca rubra & $0.02 \pm 0.01$ & $0.22 \pm 0.11$ & $1.14 \pm 0.35$ & $0.43 \pm 0.2$ & $0.64 \pm 0.30$ & $1.72 \pm 0.60$ \\
\hline Glaux maritima & $0.00 \pm 0.00$ & $0.03 \pm 0.01$ & $0.30 \pm 0.10$ & $0.19 \pm 0.11$ & $0.76 \pm 0.60$ & $0.28 \pm 0.16$ \\
\hline Halimione portulacoides & $0.01 \pm 0.01$ & $0.00 \pm 0.00$ & $0.01 \pm 0.01$ & $0.07 \pm 0.04$ & $0.25 \pm 0.13$ & $0.34 \pm 0.17$ \\
\hline Juncus gerardii(**) & $0.00 \pm 0.00$ & $0.00 \pm 0.00$ & $0.00 \pm 0.00$ & $0.00 \pm 0.00$ & $0.00 \pm 0.00$ & $1.21 \pm 1.06$ \\
\hline Limonium vulgare & $0.07 \pm 0.04 \mathbf{a}$ & $0.13 \pm 0.02 \mathbf{b}$ & $0.35 \pm 0.04 \mathrm{c}$ & $5.74 \pm 1.87 \mathbf{a}$ & $5.66 \pm 1.71 \mathbf{a}$ & $5.14 \pm 1.73 \mathbf{a}$ \\
\hline Parapholis strigosa & $0.00 \pm 0.00 \mathbf{a}$ & $0.20 \pm 0.11 \mathbf{b}$ & $7.90 \pm 0.95 \mathbf{c}$ & $0.31 \pm 0.17 \mathbf{a}$ & $0.02 \pm 0.02 \mathbf{a}$ & $0.55 \pm 0.28 \mathbf{a}$ \\
\hline Phragmetis australis & $0.01 \pm 0.01$ & $0.02 \pm 0.01$ & $1.02 \pm 0.51$ & $0.02 \pm 0.02$ & $0.06 \pm 0.02$ & $0.14 \pm 0.06$ \\
\hline Plantago coronopus & $0.01 \pm 0.01$ & $0.18 \pm 0.06$ & $0.56 \pm 0.15$ & $0.43 \pm 0.18$ & $0.09 \pm 0.04$ & $0.07 \pm 0.03$ \\
\hline Plantago maritima & $0.00 \pm 0.00$ & $0.00 \pm 0.00$ & $0.00 \pm 0.00$ & $0.14 \pm 0.14$ & $0.04 \pm 0.03$ & $0.07 \pm 0.03$ \\
\hline Puccinellia maritima & $0.01 \pm 0.01 \mathbf{a}$ & $0.45 \pm 0.11 \mathbf{b}$ & $3.77 \pm 0.69 c$ & $1.78 \pm 0.54 \mathbf{a}$ & $5.31 \pm 1.32 \mathbf{b}$ & $6.29 \pm 1.37 \mathbf{b}$ \\
\hline Sagina apetala & $0.01 \pm 0.01$ & $0.03 \pm 0.01$ & $0.26 \pm 0.14$ & $0.01 \pm 0.01$ & $0.02 \pm 0.02$ & $0.01 \pm 0.01$ \\
\hline Sagina maritima $(*)(* *)$ & $0.00 \pm 0.00$ & $0.00 \pm 0.00$ & $0.00 \pm 0.00$ & $0.00 \pm 0.00$ & $0.00 \pm 0.00$ & $0.00 \pm 0.00$ \\
\hline Salicornia europaea & $1.93 \pm 0.23$ & $11.35 \pm 1.33$ & $8.69 \pm 1.18$ & $3.57 \pm 1.18 \mathbf{a}$ & $4.99 \pm 1.51 \mathbf{a}$ & $3.33 \pm 1.21 \mathbf{a}$ \\
\hline Salicornia procumbens & $0.00 \pm 0.00$ & $3.39 \pm 0.79$ & $3.37 \pm 0.84$ & $0.00 \pm 0.00$ & $2.35 \pm 0.89$ & $1.06 \pm 0.46$ \\
\hline Salsola kali & $1.66 \pm 0.29$ & $0.51 \pm 0.14$ & $0.15 \pm 0.03$ & $1.13 \pm 0.32$ & $0.39 \pm 0.24$ & $0.12 \pm 0.03$ \\
\hline Scirpus maritimus & $0.00 \pm 0.00$ & $0.00 \pm 0.00$ & $0.00 \pm 0.00$ & $0.05 \pm 0.05$ & $0.01 \pm 0.01$ & $0.12 \pm 0.12$ \\
\hline Sedum acre & $0.03 \pm 0.01$ & $0.36 \pm 0.18$ & $0.86 \pm 0.35$ & $0.1 \pm 0.04$ & $0.26 \pm 0.13$ & $0.42 \pm 0.35$ \\
\hline Sonchus arvensis & $0.01 \pm 0.01$ & $0.09 \pm 0.06$ & $0.07 \pm 0.06$ & $0.00 \pm 0.00$ & $0.01 \pm 0.01$ & $0.01 \pm 0.01$ \\
\hline Spartina townsendii & $0.02 \pm 0.01$ & $0.18 \pm 0.13$ & $0.15 \pm 0.08$ & $3.70 \pm 1.40$ & $4.99 \pm 1.7$ & $4.47 \pm 1.63$ \\
\hline Spergularia marina & $0.00 \pm 0.00$ & $0.93 \pm 0.25$ & $2.22 \pm 0.35$ & $0.00 \pm 0.00$ & $0.09 \pm 0.03$ & $0.34 \pm 0.12$ \\
\hline Spergularia media ssp. angustata & $0.03 \pm 0.01$ & $0.11 \pm 0.04$ & $0.53 \pm 0.11$ & $1.00 \pm 0.25$ & $0.53 \pm 0.09$ & $0.20 \pm 0.04$ \\
\hline Suaeda maritima & $4.10 \pm 0.60 \mathbf{a}$ & $12.47 \pm 1.16 \mathbf{b}$ & $21.11 \pm 1.88 \mathrm{c}$ & $3.31 \pm 0.82 \mathbf{a}$ & $2.59 \pm 0.66 \mathbf{a}$ & $2.00 \pm 0.43 \mathbf{a}$ \\
\hline Triglochin maritimum & $0.00 \pm 0.00$ & $0.00 \pm 0.00$ & $0.00 \pm 0.00$ & $0.81 \pm 0.42$ & $1.86 \pm 0.83$ & $1.72 \pm 0.84$ \\
\hline
\end{tabular}




\subsubsection{Plant traits}

Seeds of early colonizers had the shortest length and seed length increased in time (Table 2.4). There was no significant difference in seed width between early and later colonizing species. Seed mass was lowest in 2003 and 2005, and highest in 2007. The weighted average of Ellenberg indicator of salinity was higher in 2003 and 2005 than in 2007. There was a significant decreasing trend in Ellenberg nitrogen indicator value from 2003 to 2007. The early colonizers had the highest Ellenberg nitrogen indicator value in the restoration site. No clear trend was detected for moisture indication number from 2003 to 2007 (Table 2.4).

Table 2.4. Repeated measurements for plant traits during succession from 2003 to 2007 in the restoration site. $\mathrm{a}, \mathrm{b}$ and $\mathrm{c}$ indicate the significant differences of traits between years.

\begin{tabular}{|c|c|c|c|c|c|c|}
\hline Plant traits & Average 2003 & Average 2005 & Average 2007 & $\mathrm{df}$ & $\mathrm{F}$ & $p$-value \\
\hline $\begin{array}{l}\text { Ellenberg nutrient } \\
\text { (nitrogen) indicator } \\
\text { value }\end{array}$ & $5.98 \pm 0.12 \mathrm{a}$ & $5.23 \pm 0.11 \mathrm{~b}$ & $5.05 \pm 0.12 c$ & 2 & 25.73 & 0001 \\
\hline $\begin{array}{l}\text { Ellenberg moisture } \\
\text { indicator value } \\
\text { Ellenberg salinity }\end{array}$ & $6.84 \pm 0.10 \mathrm{a}$ & $6.91 \pm 0.12 \mathrm{a}$ & $6.94 \pm 0.11 \mathrm{a}$ & 2 & 0.42 & 0.341 \\
\hline indicator value & $6.29 \pm 0.22 \mathrm{a}$ & $6.17 \pm 0.23 \mathrm{a}$ & $6.08 \pm 0.22 b$ & 2 & 2.17 & 0.056 \\
\hline Seed length $(\mathrm{mm})$ & $1.59 \pm 0.03 \mathrm{a}$ & $1.69 \pm 0.05 b$ & $2.02 \pm 0.03 \mathrm{c}$ & 2 & 46.18 & 0.001 \\
\hline Seed width (mm) & $1.09 \pm 0.02 \mathrm{a}$ & $1.06 \pm 0.02 \mathrm{a}$ & $1.04 \pm 0.02 \mathrm{a}$ & 2 & 2.13 & 0.122 \\
\hline Seed mass (mg) & $0.55 \pm 0.03 \mathrm{a}$ & $0.61 \pm 0.04 \mathrm{a}$ & $0.74 \pm 0.04 \mathrm{~b}$ & 2 & 420.23 & 0.001 \\
\hline
\end{tabular}

\subsection{Discussion}

Limonium vulgare, Puccinellia maritima, Elymus athericus and Spartina townsendii were the late colonizers of the restoration site. We conclude that viable seed availability might be the most important constraint for these species to act as early colonizers. Nonetheless, all species can disperse seeds via seawater well (Boorman 1967; Gray \& Scott 1977; Adam 1990; Huiskes et al. 1995). Since the seeds of these species also did not appear in the seed bank of the restoration site neither, probably the production of viable seeds is a very probable constraint to the appearance of these species as important initial colonizers in our study area, 
particular those species coming from low salt-marsh zones, i.e. Spartina townsendii, Limonium vulgare and Puccinellia maritima. The seed production estimates confirm this statement for some species only. In this study we used both seed production per unit and dominance of plant species for estimating seed availability. Despite the fact that the number of seeds of a given species available for dispersal may vary within a given site, according the parental abundance of species (Bertness et al. 1987), we wanted to estimate the global seed production per plant species by taking into account the mean number of seed per unit and a proxy of the number of units within the entire reference site. This particularly allowed us to consider the important cover of some species with low seed production. Indeed, Elymus athericus produced a relatively high seed number in the entire reference salt-marsh, indicating necessity of study on seed viability for this species. Concerning inter-annual variations in seed production, we can compare our results from 2008 to those obtained within the same study site in 2006 by Castermans (2007) for Aster tripolium. The author found that each flowering stem contained on average 89.76 capitules and each capitule contained on average 23 seeds, leading to a mean seed production with the same order of magnitude (2064 seeds per unit in 2006, standard errors are not available, vs. $1445 \pm 650$ seeds per unit in 2008). We thus argue that despite possible intra-site and inter-annual variations, our estimation of global seed production per species can be considered as a reliable general indicator of seed availability for new colonizers in the restoration site.

Despite the rapid colonization of most of the species recorded in the local species pool, the abundance of early colonizers in the restoration site was not related to their abundance in the adjacent salt-marsh. Elymus athericus was dominant in the reference marshes, while, one year after creation, its cover and presence were extremely low in the restoration site. Adversely, Suaeda maritima was the dominant and most frequent species in the restoration site in 2003, while it appeared with very low cover values in the adjacent salt-marshes. There was no 
correlation between the abundance of species in the restored and adjacent salt-marshes in the first year of colonization, indicating that the relative cover of initial colonizers is determined by seed production rather than by standing cover in the reference sites. This again confirms the first hypothesis, indicating some species despite high abundance in the surrounding area can not be first colonizers since they can not produce sufficient viable seeds.

The early colonizers of the restoration site in 2003 had the shortest seed length and lowest seed mass (second hypothesis). As the ratio of length over width (seed shape) and seed mass has been proven to be negatively correlated with seed buoyancy (Poschlod et al. 2005), it can be concluded that initial colonizers had a higher buoyancy and therefore greater dispersal ability than late colonizers. In addition, it has been demonstrated that seeds of pioneer species can disperse by other mechanisms, i.e. not only as seed, but also as seedling and adult plant (Dalby 1963; Morisawa 1999; Davy et al. 2001), increasing the chance of a higher number of seeds to disperse.

Salicornia, Salsola and Suaeda were the dominant genera in the early stages of vegetation colonization within the restoration site. In our study, these genera only comprised annual species that produce large seed numbers (Morisawa 1999; Davy et al. 2001; Wolters \& Bakker 2002). The large seed production (production of up to one million seeds per plant in Salsola kali: Duke, 1983 cited by Wolters et al. 2008 and 300-30000 per $\mathrm{m}^{2}$ in Salicornia and Suaeda: Wolters et al. 2008 and the results of this study), high viability (Davy et al. 2001), high floatability of seeds (shortest seed length and lowest seed mass) and seedling and entire plant, may explain their rapid colonization within the first year after creating the new saltmarsh.

Salinity was not shown to be the most important factor inhibiting the germination and establishment of species (part of the second hypothesis), since the Ellenberg index for salinity was between six and eight. If their seeds were transported to the restoration site and did not 
germinate, the seeds should have appeared in the seed bank. The data of the seed bank showed that some species had little or no seed bank available in the restoration site. Therefore, seed availability might be the most important factor to explain the absence of these species as initial colonizers. Nevertheless, species that colonized in 2003 and 2005, showed higher mean salt tolerance than species that colonized in 2007, indicating also higher salt tolerance for initial colonizers. Wolters et al. (2008) stated that salinity was the most important factor influencing the absence or presence of species as initial colonizers. In general, the late increase in abundance of these perennial species suggests that the increase of abundance is mainly occurring by clonal expansion.

Early colonizing species had the lowest nutrient Ellenberg indices. In this study, Salsola kali, with low nutrient-limitation tolerance, had a high abundance in the first year of colonization. However, previous studies showed that nutrient availability is rarely limiting in salt-marsh systems with the exception of those of barrier islands (van Wijnen \& Bakker 1999).

The presence of a salt-marsh close to restoration sites appears to be a pre-requisite for rapid regeneration and colonization of new salt-marsh (Thom et al. 2002; Wolters et al. 2008). Four years after creation, the restored IJzer marsh showed species composition similar to that of adjacent old salt-marsh. The speed and rate of colonization in our study area was similar to that observed in the Sieperda tidal marsh in Scheldt estuary in the Netherlands (Eertman et al. 2002). Vegetation succession took place rapidly and within 5 years, the newly created mudflat became colonized with most adjacently appearing salt-marsh species. The same pattern and progress was observed in an estuarine restoration site in the Elk River Estuary, USA (Thom et al. 2002), which was created by re-introducing a tidal inundation regime to a former embankment area. Here, the largest increase in number of species occurred 3 years after deembankment and after 5 years species diversity was similar to an adjacent reference marsh. 
In our study, most species growing on the reference salt-marsh were also recovered in the vegetation of the restoration site shortly after creation.

A review of salt-marsh restoration at different sites in north-west Europe showed that between $48 \%$ and $100 \%$ of the species present in the local species pool established in the restoration site within 1-13 years after de-embankment (Wolters et al. 2008). Compared with the regional species pool, only $26-64 \%$ of the species established in the restoration sites (Wolters et al. 2005b; Wolters 2006). Wolters et al. (2008) showed that 8 years after restoration, only $32 \%$ of the regional species pool had established in the Tollesbury restoration site and the establishment of regional salt-marsh species in new salt-marsh may take several years to be reached and established. The distance between the restoration site and existing salt-marshes and the number of inundations per year may be important determinants of the speed with which newly created intertidal areas are colonized. This is shown by at least three species present on the old salt-marsh part O2 (Fig. 1.4) of the IJzer which were not recorded in plots on the restoration site by 2007 (Artemisia maritima, Plantago maritima and Triglochin maritimum). Since at least both last species produce sufficient seeds that can float in sea water from a few hours to several months and most seeds retain their viability in salt water and germinate when exposed to suitable conditions (Reading et al. 2008), their seeds apparently did not reach the restoration site in sufficient large numbers to allow successful colonization. The lack of colonization success of these three species is most probably caused by the low connectivity between $\mathrm{O} 2$ and the restoration site (cf. Fig. 1.4), both being separated by a narrow $7 \mathrm{~m}$ TAW high dike (mean high water tide is $c a .4 .45 \mathrm{~m}$ TAW; mean spring tide high water reaches $4.86 \mathrm{~m}$ TAW). We can conclude from these findings that hydrological connectivity between seed source and sink is vital for successful colonization of salt-marsh restoration sites. Even a distance of only $1 \mathrm{~km}$ between seed source and seed sink area, which is the approximate distance at the study site between the old salt-marsh $\mathrm{O} 2$ and 
the restoration site along a strongly curved line, seems unbridgeable on the short term (six years).

\subsection{Conclusion}

The present study showed that the development of salt-marsh target species could be restricted by limited viable seed production and unfavourable soil conditions. In its current state there is a little hope that the vegetation of the restoration site will evolve towards a complete range of salt-marsh vegetation on the short run. It seems that some species such as Artemisia maritima, Plantago maritima and Triglochin maritimum would benefit from (artificial) seed introduction in the restoration site. Some species such as Spartina townsendii may not be able to perform as a pioneer species in the restoration site even if safe sites and a proper elevation level (i.e. inundation frequency) would be available. Nevertheless, it would be able to expand substantially by rhizome dispersal, followed by vegetative expansion (Garbutt \& Wolters 2008). The successful establishment and spread of this species has been well documented and was largely attributable to the species' rapid dispersal by rhizome pieces, perennial life-history and the colonization of mudflats formally unoccupied by saltmarsh plants (Gray et al. 1990). This study confirms the importance of a salt-marsh nearby to a restoration site and the importance of a continuous, short and straightforward water bridge between seed source and sink. 